
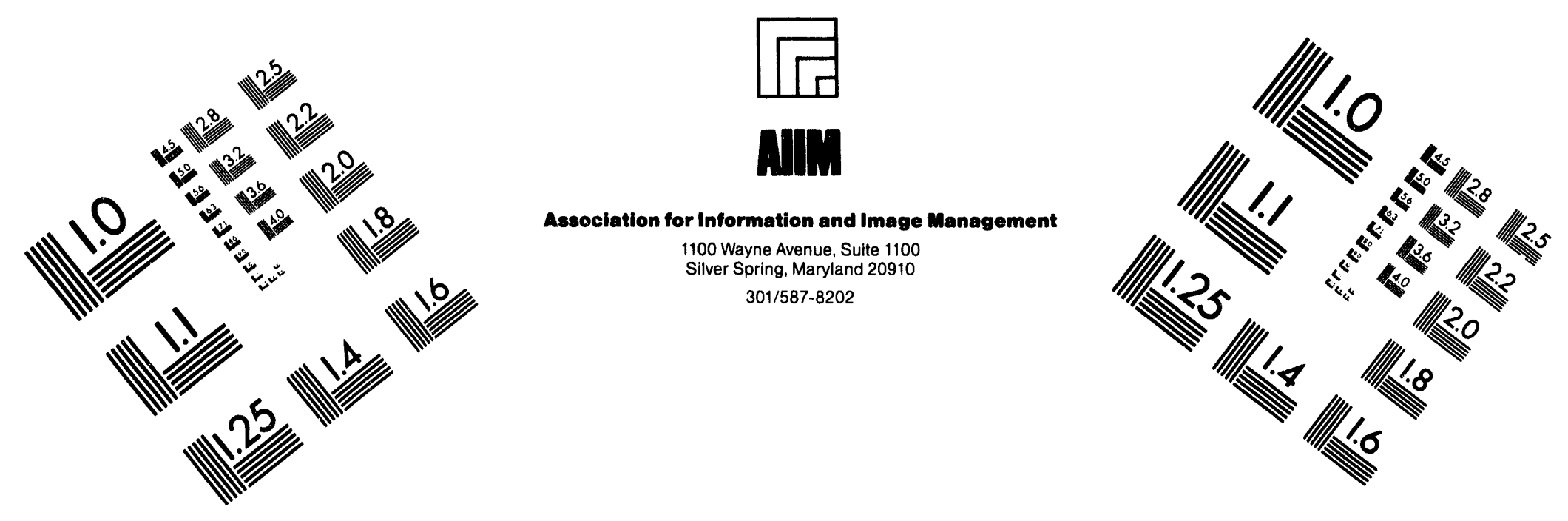

\title{
Centimeter
}

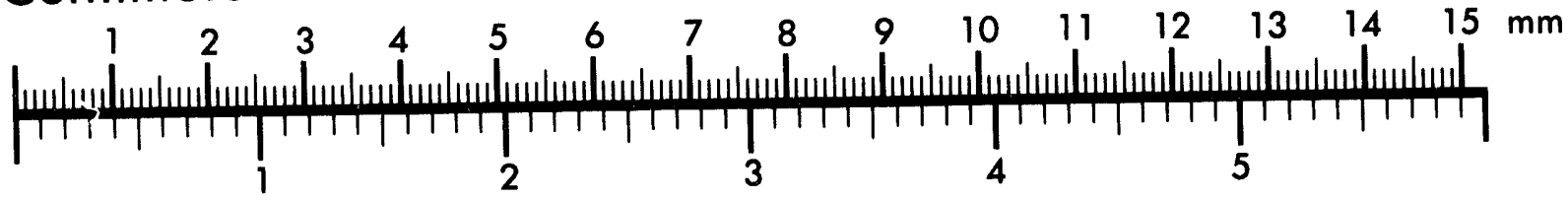
Inches
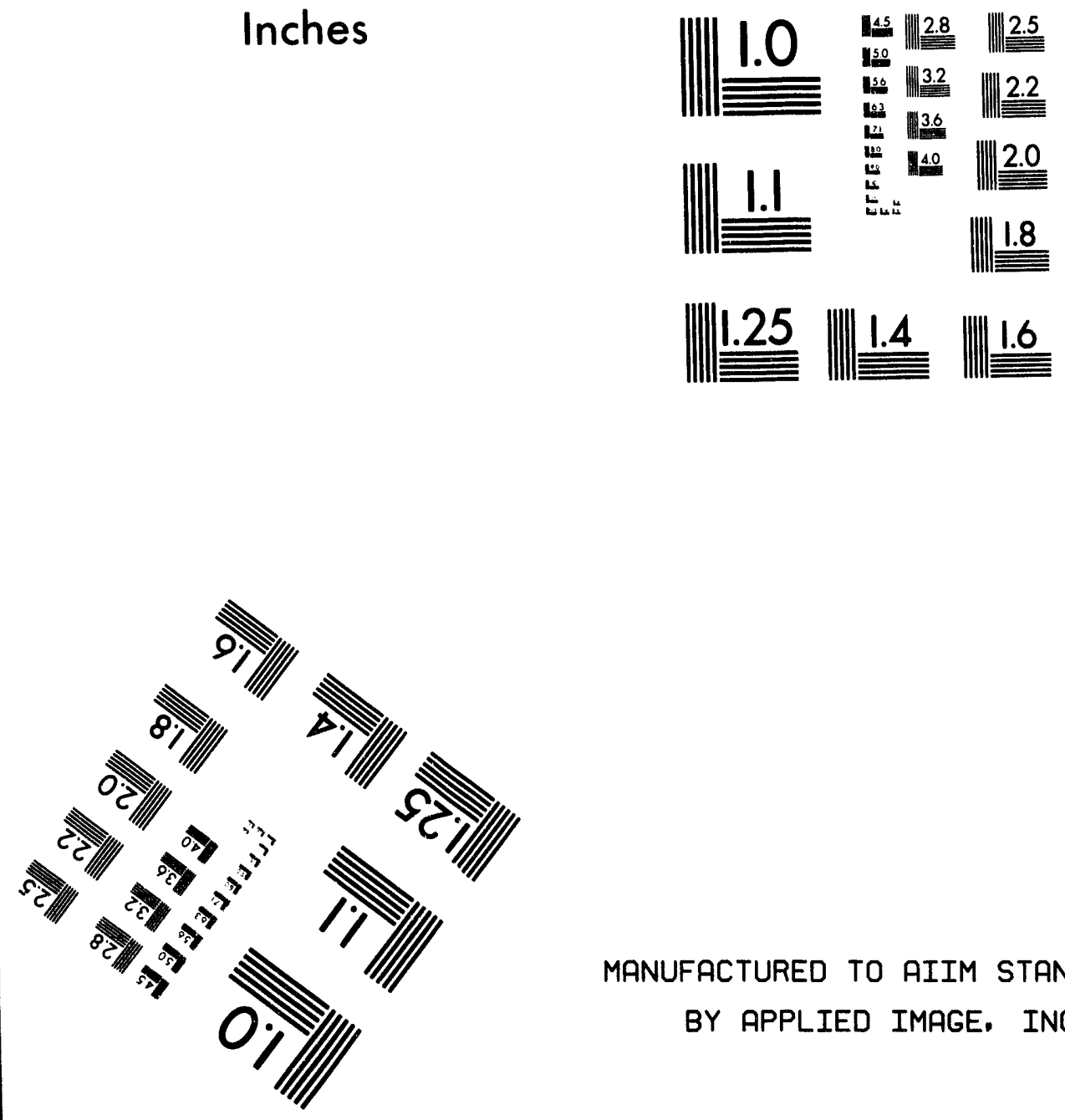

MANUFACTURED TO AIIM STANDARDS BY APPLIED IMAGE, INC.

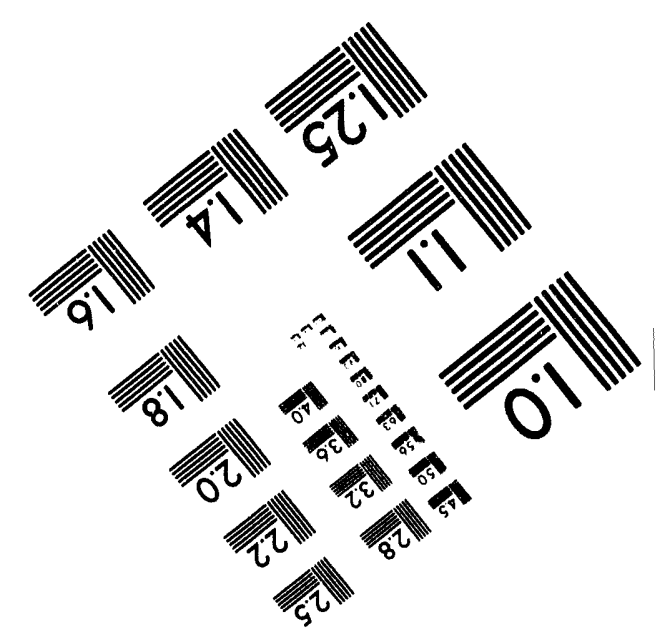





\section{Multipurpose Explosive (MPX) Drum-Shaped Packaging Design Criteria}

Date Published

May 1994

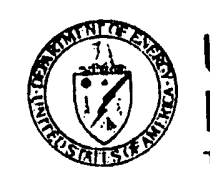

United States

Department of Energy

Transporation Management Division

Office of Environmental Management

U.S. Department of Energy
TTP Number: RL439005

Date: May 1994

Revision No.: 0 
DOE/RL-94-45

This page intentionally left blank. 


\section{EXECUTIVE SUMMARY}

In fiscal year 1993, the Transportation Management Division of the U.S. Department of Energy sponsored an engineering study, completed by Westinghouse Hanford Company, to examine the viability of a generic packaging design able to satisfy multiple explosives packaging needs. Engineering study results indicated that a box-shaped and drum-shaped (allowable outer packaging shapes) multipurpose explosive (MPX) packaging would mitigate the impact of U.S. Department of Transportation (DOT) Docket HM-181'. The MPX packaging concept was for a multi-modal, reusable outer packaging to facilitate the transport of prepackaged solid explosives, most of which are in obsolete pre-HM-181 specification packagings, inside of the MPX packaging. This document sets forth the design criteria for the drum-shaped MPX packaging.

These design criteria delineate minimum functional and regulationmandated requirements for the MPX drum-shaped packaging. Functional requirements are derived from U.S. Department of Energy site personnel involved in explosives manufacturing and shipping. Regulatory requirements are derived from DOT and International Air Transport Association transport regulations, enabling the MPX packaging to be used by commercial carriers in either highway or air transportation modes.

'DOT Docket HM-181, 1990, "Performance-Oriented Packaging Standards; Changes to Classification, Hazard Communication, Packaging and Handling Requirements Based on UN Standards and Agency Initiative; Final Rule, "Federal Register, Vo1. 55, pp. 52401-52729 (December 21, 1990). 


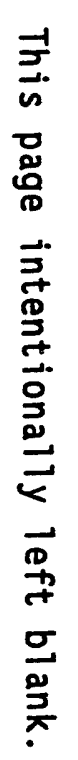

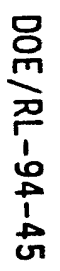




\section{CONTENTS}

1.0 INTRODUCTION . . . . . . . . . . . . . . 1-1

1.1 PURPOSE OF CRITERIA DOCUMENT . . . . . . . . . . . . 1-1

1.2 BACKGROUND . . . . . . . . . . . . . . . . . 1-1

1.3 PURPOSE OF PACKAGING ................ . . 1-2

1.4 JUSTIFICATION . . . . . . . . . . . . . . . . . 1-2

1.5 SCOPE ....................... 1 . . . .

2.0 SYSTEM REQUIREMENTS ....................... . . 2-1

2.1 MODES OF TRANSPORTATION . . . . . . . . . . . . . . . 2-1

2.2 OPERATING ENVIRONMENT . . . . . . . . . . . . . . . 2-1

2.2.1 Design Temperature Range ... . . . . . . . . 2-1

2.2.2 Maximum Design Pressure .............. . 2-1

2.2.3 Humidity ................... 2-2

2.2.4 Vibration................. 2-2

2.3 DESIGN LIFE...................... . . . . $2-2$

3.0 DESIGN REQUIREMENTS . . . . . . . . . . . . . . . . . 3-1

3.1 GENERAL . . . . . . . . . . . . . . . . . . . 3-1

3.2 FUNCTIONAL REQUIREMENTS ................ . . . . . .

3.2.1 Dimensions ................. 3-1

3.2.2 Design Payload ............... 3-1

3.2.3 Cavity Size . . . . . . . . . . . . . . 3-3

3.2.4 Cushioning/Impact Limiters . . . . . . . . . . . . 3-3

3.2.5 Reuse ................ 3-3

3.2.6 Stackability ............... 3-3

3.2.7 Drum Closure .................. 3-3

3.2.8 Pressure Boundary . . . . . . . . . . . . . 3-4

3.2.9 Structural Material ............. 3-4

3.2.10 Fabrication ............... 3-4

3.2.11 Sift-Proof . . . . . . . . . . . . . 3-4

3.2.12 Pressure-Relief Devices . . . . . . . . . . 3-5

3.2.13 Desiccant . . . . . . . . . . . . . . 3-5

3.2.14 Humidity Indication . . . . . . . . . . . . 3-5

3.2.15 Handles . . . . . . . . . . . . . . . 3-5

3.2.16 Label Holder ................. 3-5

3.2.17 Liquid Shipment .............. . 3-5

4.0 GENERAL REQUIREMENTS ...................... . . . 4-1

4.1 MATERIAL RELEASE LIMITS . . . . . . . . . . . . . . . . . . 4-1

4.2 ADDITIONAL STACKING LOADING ............... . . . $4-1$

4.3 MARKING . . . . . . . . . . . . . . . . . . 4-1

4.4 PACKAGING PERFORMANCE TEST REQUIREMENTS . . . . . . . . . . . 4-1

4.5 QUALITY ASSURANCE ................. . . 4-2

5.0 REGULATIONS, CODES, AND STANDARDS ................ . . 5-1

5.1 APPLICABLE DOE ORDERS AND REGULATIONS . . . . . . . . . . . . 5-1

5.2 APPLICABLE PACKAGING AND GROUND CARRIER REQUIREMENTS . . . . . 5-1

5.3 APPLICABLE INTERNATIONAL CIVIL AVIATION

ORGANIZATION/INTERNATIONAL AIR TRANSPORT ASSOCIATION

REGULATIONS .................... 5- . . .

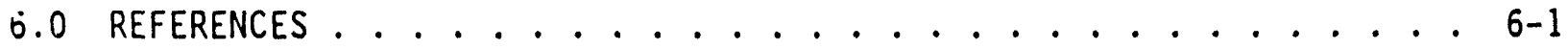




\section{DOE/RL-94-45}

\section{FIGURE}

Figure 1. MPX Drum-Shaped Packaging Concept . . . . . . . . . . 3-2 


\section{LIST OF TERMS}

DOE U.S. Department of Energy

DOT U.S. Department of Transportation

IATA International Air Transport Association

MPX multipurpose explosive (packaging)

TMD Transportation Management Division

WHC Westinghouse Hanford Company

\section{DEFINITIONS OF TERMS}

Combination packaging. A combination of packagings for transport purposes, consisting of one or more inner packagings secured in a non-bulk outer packaging.

Multipurpose Explosive (MPX) Packaging. Non-bulk, box- or drum-shaped, combination packaging designed primarily to ship inner packagings containing solid explosive substances or articles.

Payload. The total number or total gross mass of inner packages that can be loaded into an outer packaging of a combination packaging.

Pre-HM-181: Packaging and transportation regulaitions in use before october 1, 1991. The packaging requirements specify construction materials, packaging construction, and testing requirements.

Post-HM-181: Packaging and transportation regulations in use after October 1, 1991, as amended by U.S. Department of Transportation

Docket $\mathrm{HM}-181^{1}$ to require packaging design based on performance criteria.

Shipment Mobility/Accountability Collection. A database of hazardous and radioactive shipments within the U.S. Department of Energy complex of sites.

Specification Packaging. A packaging conforming to one of the pre-HM-181 specifications or standards for packaging in 49 CFR 178 or 179.

'DOT Docket HM-181, 1990, "Performance-Oriented Packaging Standards; Changes to Classification, Hazard Communication, Packaging and Handling Requirements Based on UN Standards and Agency Initiative; Final Rule, " Federal Register, Vol. 55, pp. 52401-52729 (December 21, 1990). 


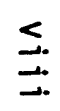

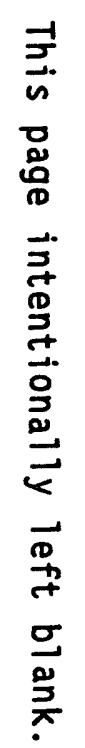

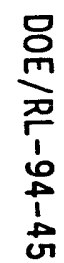


DOE/RL-94-45

\section{MULTIPURPOSE EXPLOSIVE (MPX) DRUM-SHAPED PACKAGING DESIGN CRITERIA}

\subsection{INTRODUCTION}

\subsection{PURPOSE OF CRITERIA DOCUMENT}

This document establishes the minimum functional and performance requirements for a drum-shaped, multipurpose explosive (MPX) outer paskaging design. The MPX packaging will be transported by major domestic commercial air carriers or by ground carriers on public highways. The functional requirements are considered necessary by personnel involved in explosives manufacturing and shipping at U.S. Department of Energy (DOE) sites. The performance requirements are established by applicable U.S. Department of Transportation (DOT) and International Air Transport Association (IATA) regulations.

\subsection{BACKGROUND}

DOT Docket HM-181, issued in December 1990 , contained changes to packaging and transportation regulations (49 CFR 171-180) that are being phased in over a five-year period that began on October 1, 1991 (DOT 1990). The DOT regulatory changes were made to replace pre-HM-181 specification packagings with packagings that meet performance criteria. These changes will align U.S. regulations with similar international regulations.

Newly developed explosive substances or articles are assigned a shipping description, class, and classification code by authorized government agencies. The shipping description establishes which inner and outer packagings are a llowable for shipment. DOT Docket HM-181 reclassified a large number of existing explosives. Consequently, many existing pre-HM-181 specification packagings will become obsolete unless they can be shown to satisfy performance packaging requirements.

The DOT Docket HM-181 changes offer greater flexibility in the allowable outer packaging shape (i.e., box or drum) than the old pre-HM-181 specification packagings. Another change resulting from DOT Docket HM-181 is the introduction of variation 2 selective-testing provisions

(49 CFR 178.601[g][2]). Variation 2 provisions enable an outer packaging to be used to transport "...inner packagings of any type, for solid or liquids..." without retesting each different inner/outer packagi, $y$ configuration. If the variation 2 selective-testing provisions are not used, each inner/outer packaging configuration will have to go through all performance-oriented packaging tests.

Stockpiled explosive substances or articles are typically stored in pre-HM-181 specification packagings. Some explosives are transported by exemption, and each exemption must be periodically reviewed and renewed. With DOT Docket HM-181 changes to packaging requirements, renewal of packaging exemptions is uncertain. To limit the amount of repackaging of explosives packaged in obsolete pre-HM-181 specification packagings, or the designing of 
new packaging when an exemption is not renewed, the MPX packaging concept using the variation 2 selective-testing provisions was developed. Also, the MPX packaging could be used for new explosive or nonradioactive hazardous materials under post-HM-181 hazardous material transportation regulation changes.

The MPX packaging concept combines the increased flexibility in allowable outer packaging shape with the variation 2 selective-testing provision. Certified MPX packaging could be used to ship many prepackaged explosives and hazardous materials. In addition, unique explosive articles, or explosives for which the exemption has not been renewed, could be transported using MPX packaging. Two outer packaging shapes, one box- and one drum-shaped, wil1 be developed as documented in Explosives Generic Packaging - Box or Drum, Draft (WHC 1993a). The MPX box-shaped packaging is described in Multipurpose Explosive (MPX) Box Packaging Design Criteria, Draft (WHC 1993b).

\subsection{PURPOSE OF PACKAGING}

MPX packaging is a variation 2, non-bulk, outer packaging that will enable transportation of any inner packaging by either highway or air carriers. The MPX packaging will be designed as a performance packaging and will meet all regulatory requirements. The design organization will provide a completed, documented, and verified packaging design. An integral part of the design, analyses, and/or test data will be provided to demonstrate the design meets all requirements of this document.

Packaging design deliverables include the following, as a minimum:

1. Complete, detailed, end product drawings that have been reviewed and approved by authorized personnel and are suitable for use in fabrication

2. Formally documented and verified analyses and/or test data

3. A fabrication specification that defines requirements to the fabricator that cannot be communicated through the design drawings

4. A description of the package and its salient features

5. Operating instructions that clearly identify any safety, inspection, or performance precautions and any special tooling required.

\subsection{JUSTIFICATION}

In fiscal year 1993, Westinghouse Hanford Company (WHC) was funded, under Technical Task Plan RL439005, by the Transportation Management Division (TMD) of the DOE to examine the feasibility of developing a generic drum-shaped and box-shaped packaging for explosives transportation. The draft engineering study, Explosives Generic Packaging - Box or Drum (WHC 1993a), concludes that development of box-shaped outer packaging is a higher priority than development of drum-shaped outer packaging, but that both packagings are required by explosives manufacturers and shippers in the DOE complex of sites. The TMD approved the continued development of the MPX packaging concept as 
proposed by WHC. The draft MPX box-shaped packaging design criteria was promulgated in Multipurpose Explosive (HPX) Packaging Design Criteria (WHC 1993b), and this design criteria for MPX drum-shaped packaging is the third step in the packaging design development.

\subsection{SCOPE}

This document provides criteria for the design of a non-bulk, drumshaped, outer packaging. However, the MPX packaging and this document are not intended to encompass forbidden materials; forbidden explosives; liquid explosives; liquid hazardous materials; Hazard Class 6, Division 6.2, infectious substances (etiologic agents); or Hazard Class 7 , radioactive materials in any quantity.

The regulations identify requirements for non-bulk packaging. If explosive materials are to be transported, only one inner package containing an explosive substance or article can be shipped in one MPX outer packaging because of explosives classification requirements. However, the number of inner packagings contained in the MPX outer packaging when nonexplosive solid hazardous materials are transported must be appropriate for the hazardous materials and is limited only by packaging size, DOT and IATA packaging requirements, or carrier requirements.

Inner packagings may be of any type when used with the MPX packaging but must be appropriate for the article or solid material being shipped and cannot be more fragile than the inner packagings used during the testing of the packaging. Inner packaging design is not relevant to these criteria and is not addressed herein.

Fabricated MPX drum-shaped packagings will be available by October 1, 1996. 


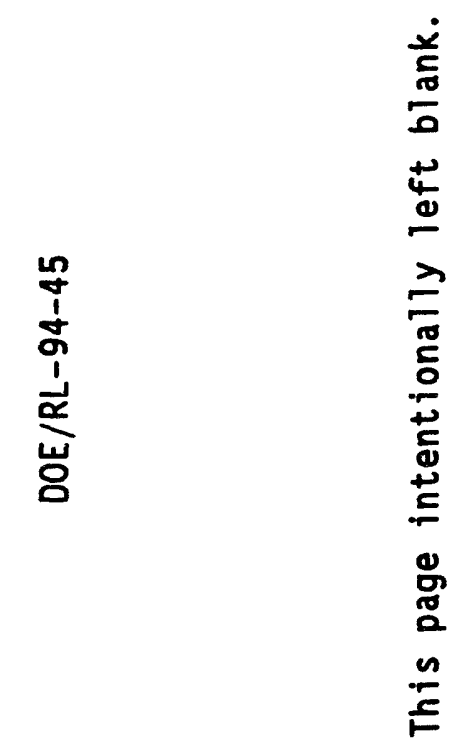




\subsection{SYSTEM REQUIREMENTS}

The MPX drum is a combination packaging system. It consists of any inner packaging and the MPX outer packaging. It is not designed as a single packaging into which hazardous materials can be packed directly. The certified MPX packaging will provide shippers with a variation 2 outer packaging, tested and certified for shipping solid contents in appropriate inner packagings. The packaging will be marked with appropriate variation 2 markings that indicate the maximum gross mass of inner packagings is 1 imited to $45 \mathrm{~kg}(100 \mathrm{lb})$. The variation 2 outer packagings will be steel with welded seams, testable 0-ring head-body seals, and integral cushion/impact limiters. other outer packaging features include a tri-directional G-load indicator, a shipping label holder, and a removable head. The MPX outer packaging will be designed for ease of cleaning and replacement of damaged dunnage.

\subsection{MODES OF TRANSPORTATION}

In the original technical task plan, the MPX packaging concept was intended for multi-modal transportation. To limit the design criteria to those modes in which the certified packaging will most likely be used, the MPX concept is limited to domestic highway and air transportation requirements. The results of a Shipment Mobility/Accountably Collection report for all sites within the DOE complex during calendar years 1990 through 1992 indicated that less than $1 \%$ of inbound or outbound hazardous nonradioactive shipments was transported by either rail or water.

\subsection{OPERATING ENVIRONMENT}

The MPX packaging shall be designed to perform in the most restrictive ambient environment to which the packaging would be exposed during transport. The design basis environment is described below. The effectiveness of the package shall not be substantially reduced at any point within the operating environment. For example, pressure boundaries shall be designed to ensure there is no loss of seal through the entire temperature range. Material properties of the fabricated package shall remain ductile within the operating environment.

\subsubsection{Design Temperature Range}

The temperature range during air transport is expected to be at least as extreme as during ground transport, so air transport is the basis of packaging design. The temperatures of the environment during transport may range between $-40^{\circ} \mathrm{C}\left(-40^{\circ} \mathrm{F}\right)$ and $55^{\circ} \mathrm{C}\left(131^{\circ} \mathrm{F}\right)$ (IATA 1994).

\subsubsection{Maximum Design Pressure}

The pressure range during air transport is expected to be more extreme than that during ground transport, so air transport is the basis of packaging design. The maximum design pressure for the primary, or pressure-retaining, 
boundary is based on the pressure reduction encountered under extreme flight conditions, which is $68 \mathrm{kPa}\left(10 \mathrm{lb} / \mathrm{in}^{2}\right)$ gauge (IATA 1994).

\subsubsection{Humidity}

The packaging shall be designed to operate in an ambient environment that is fully saturated at design operating temperatures. The packaging shall be designed to minimize pooling of water on the packaging exterior; in handle recesses, for example. There shall be no migration of water from the package exterior to the package interior.

\subsubsection{Vibration}

The packaging shall be designed to withstand vibrations expected to occur during ground and air transport. The packagings may be exposed to vibrations ranging from $5 \mathrm{~mm}$ amplitude at $7 \mathrm{~Hz}$ (corresponding to $1 \mathrm{~g}$ acceleration) to $0.05 \mathrm{~mm}$ amplitude at $200 \mathrm{~Hz}$ (corresponding to $8 \mathrm{~g}$ acceleration) (IATA 1994) for one hour (49 CFR 178.608 [b][3]).

\subsection{DESIGN LIFE}

The MPX packaging shall be designed to be reusable and will have a useful service life of five years. Within normal conditions of handling, environment, and transport, service life means that an adequately maintained packaging will be reusable for a continuous five-year period. The body and lid shall be designed to sustain impacts incident to transport during that period. Hardware (such as latches and access hardware) shall be designed to be replaceable. Impact cushioning on the inside and/or outside of the packaging will be designed to protect the package contents and the packaging, and will be sacrificed in performing its function. Sacrificial components shall be designed to perform their function and to be replaced. 


\subsection{DESIGN REQUIREMENTS}

\subsection{GENERAL}

The MPX drum shall meet all DOT requirements for a variation 2 outer packaging that is part of a combination packaging system (49 CFR 178.601[g][2]). (See Figure 1.) The outer packaging shall be designed to be reusable and repairable. It will be designed for solid, nonbulk explosives or solid, hazardous material shipments. The MPX drum shall be air transportable and shall meet all DOT and IATA requirements for air shipment (49 CFR 173.27 and IATA 1994). The MPX drum will provide shippers with the largest payload volume for inner packagings within the dimensional constraints, fabrication-material structural limits, performance testing requirements, and other restrictions of the criteria. Radioactive, mixed hazardous materials, or liquids cannot be shipped in the MPX packaging.

\subsection{FUNCTIONAL REQUIREMENTS}

\subsubsection{Dimensions}

The MPX drum will be a cylinder with the following internal dimensions: diameter, $18 \mathrm{in.}(46 \mathrm{~cm})$; height, $28 \mathrm{in.}(71 \mathrm{~cm})$ (standard $30-\mathrm{gal}$ drum size).

\subsubsection{Design Payload}

The MPX drum is the variation packaging. Selective-testing requirements state that the combination packaging, from which the variation packaging is derived, will be tested with twice the maximum gross weight of the inner packagings. The maximum gross weight of the inner packagings that can be transported in an MPX drum is $45.4 \mathrm{~kg}(100 \mathrm{lb})$. Therefore, the MPX packaging design must be able to successfully meet all performance requirements with a $90.8 \mathrm{~kg}(200 \mathrm{lb})$ design payload.

The heaviest possible AN can (a commonly used explosives packaging) that will fit into the MPX drum has a maximum capacity of $34 \mathrm{~kg}(75 \mathrm{lb})$, and the weight of the AN can itself will not exceed $7 \mathrm{~kg}$ (15 lb). An $11 \%$ mass contingency is provided, resulting in a maximum useful payload weight of $45 \mathrm{~kg}$ $(100 \mathrm{ib})$.

The inner packagings used for testing are to be "fragile." The size of the fragile containers will be determined based on the shipping history of the DOE sites. 
DOE/RL-94-45

Figure 1. MPX Drum-Shaped Packaging Concept.

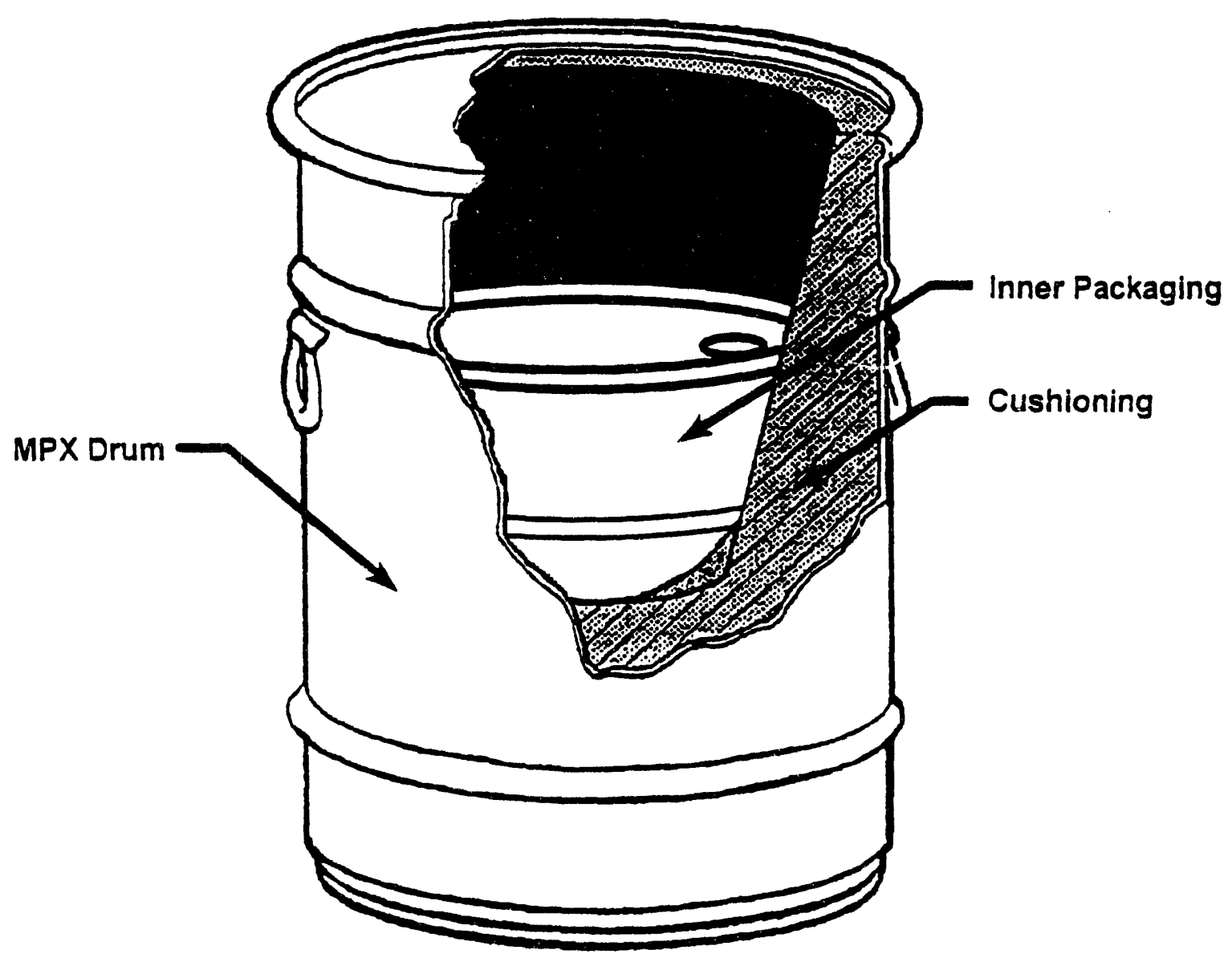




\subsubsection{Cavity Size}

The MPX drum will be designed to carry a minimum of one inner packaging with an outer diameter of $39 \mathrm{~cm}(15.5 \mathrm{in}$.) and a height of $55 \mathrm{~cm}$ (21.5 in.). These outside dimensions do not include the area necessary to adequately handle/lower the inner package into the outer packaging. They al so do not include any energy absorption media that may be required to cushion the loads imparted to the packaging during normal transport.

\subsubsection{Cushioning/Impact Limiters}

The packaging may be designed with passive impact limiters or shock limiting devices. These impact limiters may be located on the inside, outside, or on both the inside and outside of the MPX packaging. The impact limiters or dunnage will be designed to prevent breakage of the inner packagings if an MPX drum loaded with $91 \mathrm{~kg}(200 \mathrm{lb})$ (twice the gross mass of any potential inner packaging) were dropped from $1.8 \mathrm{~m}(5.9 \mathrm{ft})$. Impact limiters will be designed to absorb the kinetic energy of the loaded packaging in any orientation and to remain attached until the package comes to rost after decelerating from a fall. Impact limiters are sacrificial and replaceable; they cannot be repaired. Once an impact limiter has performed its function, it will indicate permanent damage. The impact-limiting material will be designed to be easily replaced.

\subsubsection{Reuse}

The MPX outer packaging will be designed for reuse. As such, hardware and sacrificial components will be designed to be replaceable if they are damaged. The minimum thickness of the MPX drum is $1.8 \mathrm{~mm}(0.071 \mathrm{in}$.), and this thickness must be embossed on it (49 CFR 173.28[b][4]).

\subsubsection{Stackability}

The MPX drum packaging will be stackable, such that an empty MPX drum can be placed for 24 hours at the bottom of a $3-\mathrm{m}-(10-\mathrm{ft}-)$ high stack of MPX drums loaded with the weight used for the drop test (49 CFR 178.606 and IATA 1994).

\subsubsection{Drum Closure}

The head of the MPX drum will be completely removable. Under all design basis parameters, the head will be held closed and sealed with either an external clamp and lock ring or a threaded fastener. If the external clamp is selected, a suitable gasket must be included with the closure device. If the threaded fastener is selected, either a suitable gasket must be included or another feature must be incorporated to prevent the ingress of material into the threads (49 CFR 173.60[b][7]). The closures will be lockable and have provisions for a tamper-indicating seal. This locking closure must not require any type of key. All closures will be designed such that the probability for release or leakage of explosive or hazardous material is as low as practically achievable. 


\subsubsection{Pressure Boundary}

The MPX drum-shaped packaging will be designed as a pressure-retaining boundary. The containment boundary will be designed to prevent leakage that may be caused by changes in altitude and temperature during transportation by aircraft (49 CFR 173.27[C]). These extremes are defined as temperatures of $-40{ }^{\circ} \mathrm{C}$ and $55^{\circ} \mathrm{C}\left(-40^{\circ} \mathrm{F}\right.$ and $\left.130^{\circ} \mathrm{F}\right)$ and a pressure reduction of $68 \mathrm{kPa}$ (10 lb/in. ${ }^{2}$ ) gauge (IATA 1994).

\subsubsection{Structural Material}

The MPX drum will be fabricated from carbon or stainless steel of 'nown composition and properties. Steel provided will be manufactured in accordance with a recognized national standard, such as that of the American Society of resting and Materials, or military specification. A mill certification will be provided by the steel manufacturer as evidence the material is as specified. Carbon steel will be paintable in accordance with American Institute of Steel Construction procedures. All other materials used in fabrication will be specified in accordance with applicable recognized national or commercial standards (such as the American National Standards Institute or the Society of Automotive Engineers). The steel will be thick enough and of a metallurgical composition that will enable the joints to be welded economically. Where possible, the body and head will be constructed without seams or use of rivets (LLNL 1991).

The drum-shaped container will be fabricated of the steel that is least reactive with the hazardous materials that could be shipped in the inner packaging.

\subsubsection{Fabrication}

The MPX drum will be designed for mass production with emphas is on modular construction to ease fabrication and assembly. Structural, seam, and seal welds and weld joints will be made in accordance with appropriate recognized national standards, such as those of the American Welding Society or American Society of Mechanical Engineers. All welds will be ground flush to the specified finish. A manufacturing or value engineering analys is will be performed to ensure ease of fabrication and economy of mass production. To facilitate cleanup in the event of a spill, the interior surface of the packaging will have a finish that allows for easy cleaning.

\subsubsection{Sift-Proof}

The MPX drum will be designed to be sift-proof. The packaging, as assembled for transport, will be able to contain the solid contents from any damaged inner packaging. 


\subsubsection{Pressure-Relief Devices}

The MPX drum will have a pressure-relief device that can be used to equalize pressure between the interior of the packaging and the ambient environment before the MPX drum is opened.

\subsubsection{Desiccant}

The MPX drum will contain a desiccant material that will limit the moisture content of the interior of the packaging.

\subsubsection{Humidity Indication}

The MPX drum will have a gauge, which can be read from the outside of the container, that accurately indicates the relative humidity of the inside of the MPX drum. This device will be flush with the outside of the container.

\subsubsection{Handles}

The MPX drum will have one or more lifting handles on opposing sides. Each handle will be designed to carry 1.5 times the gross weight of the loaded package. The lifting handles will be sturdy and conveniently located so one person can carry the empty packaging.

Handles located on the lid of the packaging will be designed so that the loaded package cannot be lifted from the head. Handles on the head are to facilitate grasping of the head during its removal from the body. Handles on the head will be marked as "Nc Lift" points with a permanent contrasting paint adjacent to the lid handle.

All handles will be snag-proof during transport.

\subsubsection{Label Holder}

The MPX drum will have provisions for a reusable label holder for shipping documents. The label holder will be able to accommodate several standard letter-sized $(21.6 \mathrm{~cm} \times 28 \mathrm{~cm}[8.5 \mathrm{in} . \times 11$ in.]) pages and will protect them from getting wet, lost, or destroyed. The label holder will be located on the exterior of the drum body or lid so as to sustain minimal damage during normal handling. If damaged, the label holder will be readily repairable or replaceable.

\subsubsection{Liquid Shipment}

The MPX drum will not be designed to ship liquids in the inner container. 
DOE/RL-94-45

This page intentionally left blank. 


\subsection{GENERAL REQUIREMENTS}

The MPX drum will be designed to meet the requirements of both 49 CFR 178.504, the general requirements for steel drums, and 49 CFR 173.28, the requirements for reuse of packagings. The components (such as 1atches, hinges, and other hardware) used in the design of the MPX drum will be offthe-shelf manufactured items wherever possible. Major parts (e.g., 1id, body, and impact limiter) will be designed and toleranced to be interchangeabie. Each complete-as-manufactured MPX drum will have a model serial number permanently affixed.

The MPX drum system, as prepared for shipment, will be designed to be as rigid (inflexible) as practicable to prevent excessive loading of the inner packaging during normal conditions of transport. The inner cavity volume of the MPX drum will be large enough to sufficientiy ensure that the inner packagings are not pinched and that excessive pressure is not being applied to the inner packagings as the lid is being sealed.

\subsection{MATERIAL RELEASE LIMITS}

Packagings will be designed to be closed and secured (minimal movement of inner packagings) so that there is no identifiable release of hazardous materials to the environment (49 CFR 173.24[b][1]) under normal conditions of transport. The package will not vent during transportation (49 CFR 173.24[g][1]).

\subsection{ADDITIONAL STACKING LOADING}

The MPX drum will be designed to withstand stacking loads such as those sustained by an empty MPX drum can placed, for 24 hours, at the bottom of a 3-m- (10-ft-) high stack of MPX drums loaded with the weight used for the drop test (49 CFR 178.606 and IATA 1994). The lid and body structure will be designed to withstand bending and tie-down loads if they are greater than the structural loads caused by stacking.

\subsection{MARKING}

Each MPX drum will be permanently marked, as required in 49 CFR 178.502, 49 CFR 178.503, and 49 CFR $178.601(\mathrm{~g})(2)$ ( $v i i)$, with United Nations markings appropriate for the weight of inner packagings tested under the selectivetesting requirements. The markings will be applied to the head and body of the drum. The markings can be placed on separate permanent labels or on nameplates that meet the character size requirements and are affixed to the head and body.

\subsection{PACKAGING PERfORMANCE TEST REQUIREMENTS}

All packaging components requiring testing will be capable of meeting variation 2 (49 CFR 178.601[g][2]) requirements. Components that provide the primary containment boundary must be capable of withstanding temperature 
extremes of $-40^{\circ} \mathrm{C}$ and $55^{\circ} \mathrm{C}\left(-40^{\circ} \mathrm{F}\right.$ and $130{ }^{\circ} \mathrm{F}$ ) (IATA 1994) and a pressure reduction of $68 \mathrm{kPa}\left(10 \mathrm{lb} / \mathrm{in}^{2}\right.$ ) gauge (IATA 1994). The drop tests will be conducted with a payload gross mass of $91 \mathrm{~kg}(200 \mathrm{lb})$.

The package must be capable of withstanding vibration that varies from 5-mm amplitude at 7 cycles per second (corresponding to $1 \mathrm{~g}$ acceleration) to $0.05-\mathrm{mm}$ amplitude at 200 cycles per second (corresponding to $8 \mathrm{~g}$ acceleration) (IATA 1994).

\subsection{QUALITY ASSURANCE}

The organizations responsible for MPX packaging design, testing, and fabrication must have a quality plan, subject to review, for each task that they are performing. The quality plan can be in accordance with a recognized quality standard (e.g., ISO 9000) and must ensure that the requirements of this document, DOE orders, and DOT regulations are correctly translated in specifications, drawings, fabrication procedures, and operating procedures. The operating procedures will provide instructions for package use (completeness criteria) to ensure that the same level of protection to workers, the public, and the environment is maintained each time the MPX packaging is used throughout its design life. These requirements are to aid the shipper in specifically identifying operating parameters (e.g., location of cushioning material, reuse examination requirements, etc.) that must be met to ensure the necessary safety requirements when the packaging is offered for transport.

Any design changes, including field changes, must be subject to the same design control measures applied to the original design.

The design organization will fulfill the role of manufacturer as described in 49 CFR 178.2, 49 CFR 178.502, 49 CFR 178.503, and 49 CFR 178.601, assuming full responsibility for the adequacy of the packaging design and ensuring that regulatory requirements are met. 


\subsection{REGULATIONS, CODES, AND STANDARDS}

\subsection{APPLICABLE DOE ORDERS AND REGULATIONS}

The DOE orders address handling and transportation of hazardous material. Compliance with these orders is required for all DOE contractors. The DOE orders also require compliance with regulations of other government agencies and the commercial carriers. The applicable regulations of other government agencies and the commercial carriers are identified in the following text. Specific DOE orders are not identified as they provide no specific packaging design guidance and they are in a state of change.

The MPX drum will be transported by commercial highway and air carriers. Therefore, all applicable transportation requirements of the DOT, the DOE, and the individual carriers must be met.

\subsection{APPLICABLE PACKAGING AND GROUND CARRIER REQUIREMENTS}

Applicable packaging and ground carrier raquirements of the DOT include the following:

- 49 CFR 100-199, "Research and Special Programs Administration, Department of Transportation"

- DOT regulations governing the packaging and offsite transportation of hazardous materials, explosive substances and articles.

\subsection{APPLICABLE INTERNATIONAL CIVIL AVIATION ORGANIZATION/INTERNATIONAL AIR TRANSPORT ASSOCIATION REGULATIONS}

Applicable requirements of the air carriers include the following.

- 9284-AN/905, Technical Instructions for the Safe Transport of Dangerous Goods by Air, as amended (ICAO 1990), contains regulations developed by the International Civil Aviation Organization to provide for the safe transport of hazardous materials by air.

- Dangerous Goods Regulations, as amended (IATA 1994), developed by the IATA, contains the requirements, including packaging, for shipping radioactive and other hazardous materials by air. 
DOE/RL-94-45

This page intentionally left blank.

5-2 


\subsection{REFERENCES}

49 CFR 100-199, "Transportation," Code of Federal Regulations, as amended.

DOT Docket HM-181, 1990, "Performance-Oriented Packaging Standards; Changes to Classification, Hazard Communication, Packaging and Handling Requirements Based on UN St andards and Agency Initiative; Final Rule," Federal Register, Vol. 55, pp. 52401-52729 (December 21).

IATA, 1994, Dangerous Goods Regulations, 35th edition, International Air Transport Association, Montreal, Canada.

ICAO, 1990, Technical Instructions for the Safe Transportation of Dangerous Goods by Air, 9284-AN/905, International Civil Aviation Organization, Montreal, Canada.

ISO 9000, 1987, Quality Management and Quality Assurance Standards Guidelines for Selection and Use, International Organization for Standardization, Geneva, Switzeriand.

LLNL, 1991, DOE Explosives Safety Manual, DOE 06194, Lawrence Livermore National Laboratory, Livermore, California.

WHC, 1993a, Explosives Generic Packaging - Box or Drum, DOE/RL-93-55, Draft, Westinghouse Hanford Company, Richland, Washington.

WHC, 1993b, Multipurpose Explosive (MPX) Box Packaging Design Criteria, DOE/RL-93-103, Draft, Westinghouse Hanford Company, Richland, Washington. 
DOE/RL-94-45

This page intentionally left blank. 


\section{DISTRIBUTION}

Number of Copies

OFFSITE

1

$\frac{\text { Department of Energ/ - EH } 33.2}{19901 \text { Germantown Road }}$

G. Meyers

EH 33.2

3 Department of Energy - EM 261

12800 Middlebrook Road

Germantown, Maryland 20874

L. G. Blalock

EM 261

M. J. Conroy

EM 261

E. B. McNei1

EM 261

\section{ONSITE}

$\frac{\text { Pacific Northwest Laboratory }}{\text { P. O. Box } 999}$

Richland, Washington 99352

Technical Files

$\mathrm{K} 1-11$

3

U. S. Department of Energy

Richland Operations office

P. 0. Box 550

Richiand, Washington 99352

R. F. Guercia

R3-80

S. K. Moy

Public Reading Room

R3-80

A1-65

32 Westinghouse Hanford Company

P. 0. Box 1970

Richland, Washington 99352

W. S. Edwards (25)

G2-02

R. P. Genoni

G2-02

Central Files

Document Processing and Distribution (2)

Information Release Administration (3)

L8-15

L8-04

A3-36 


\section{DOE/RL-94-45}

This page intentionally left blank. 

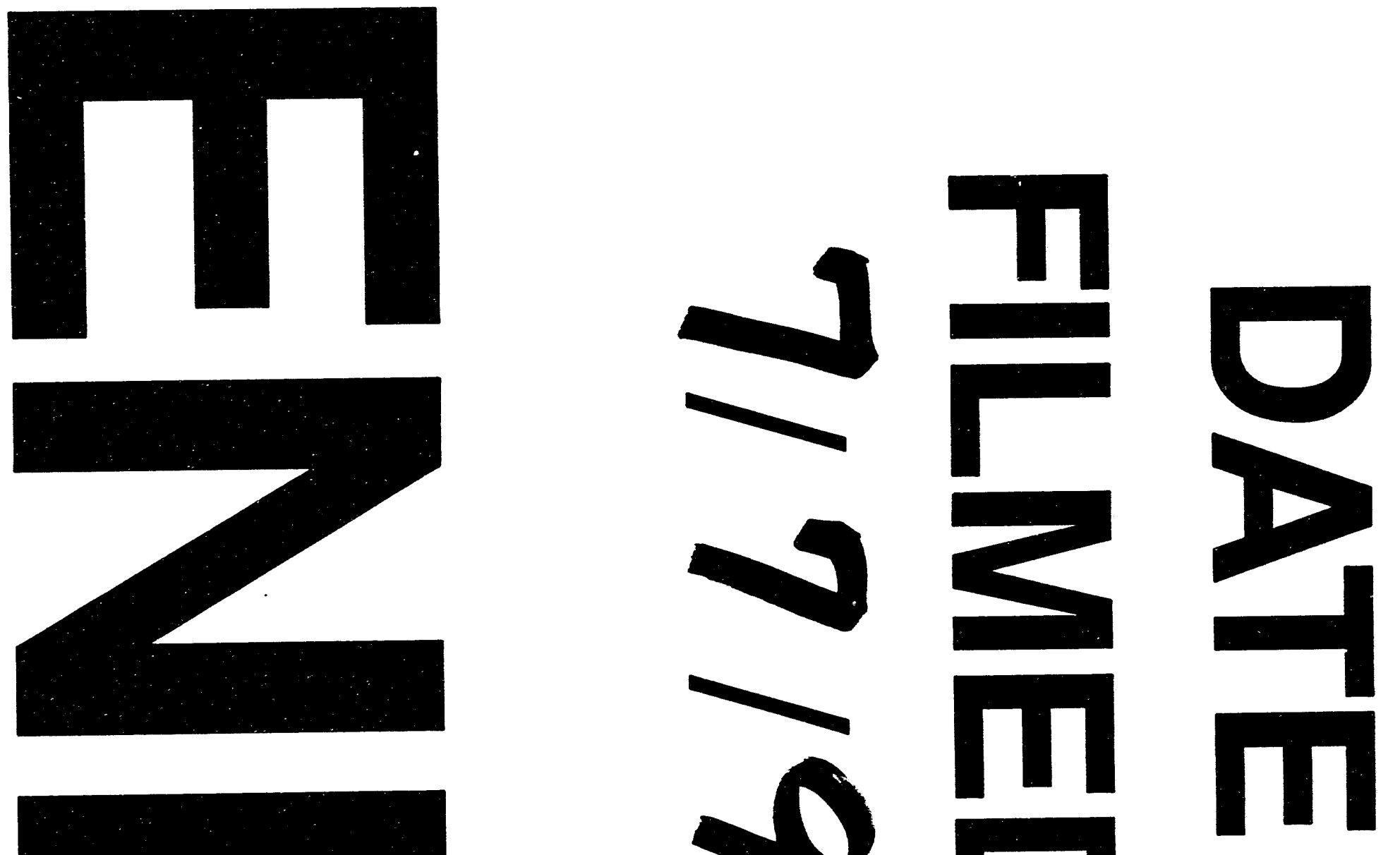

$\Sigma$
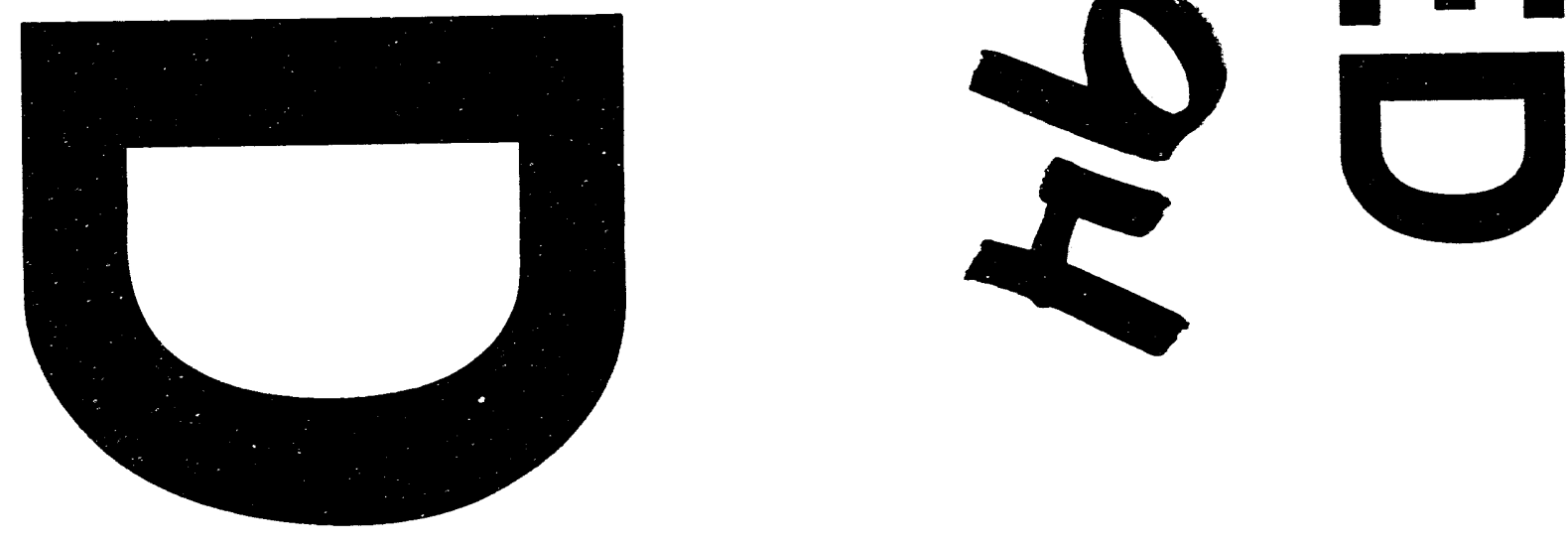
